\title{
К ВОПРОСУ О ДОПОЛНИТЕЛЬНЫХ РАСХОДАХ НА ДЕТЕЙ
}

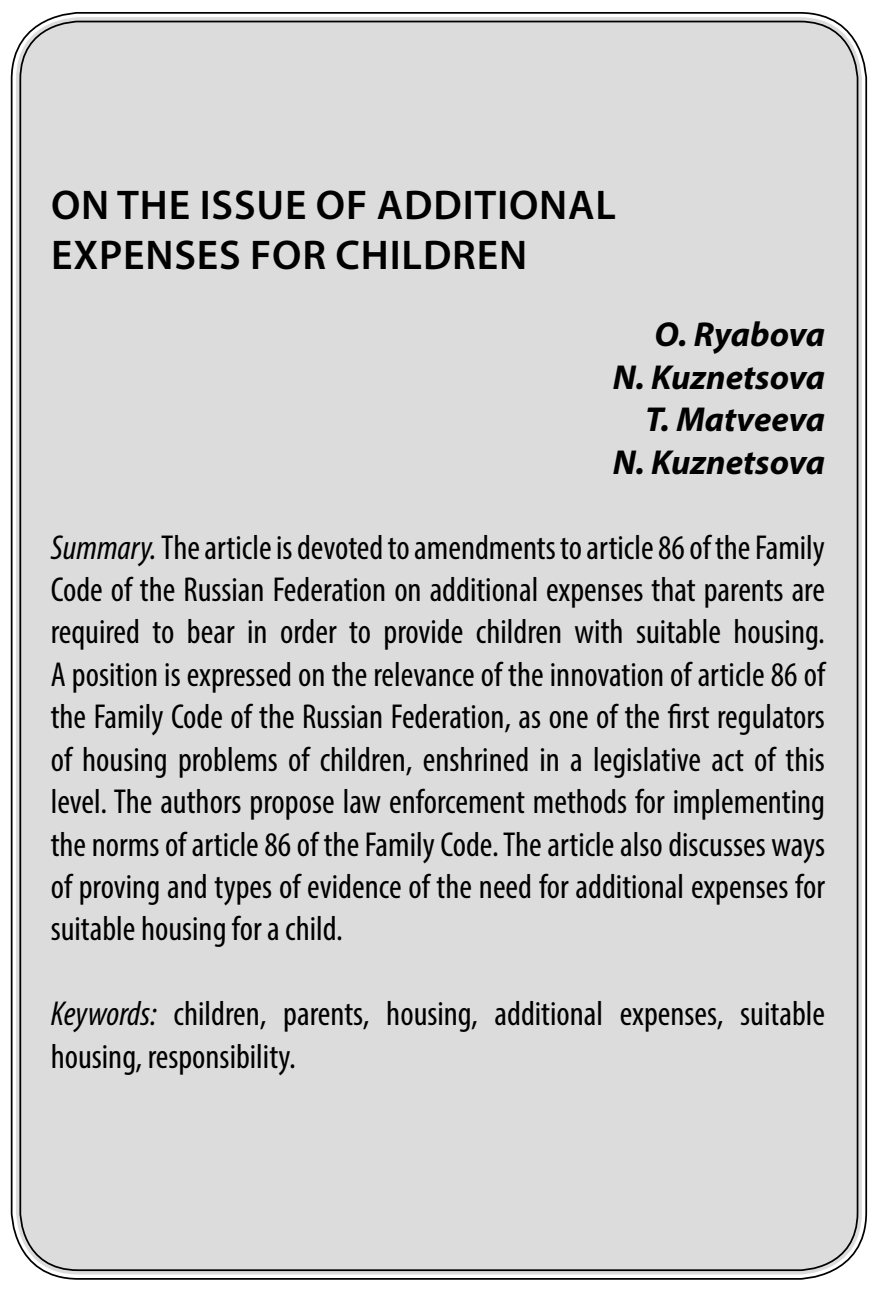

B современных реалиях необходимо понимать, что благополучию детей нужно уделять достаточное количество внимания. В соответствии со статьей 56 Семейного Кодекса $P Ф$, ребенок имеет право на защиту своих прав и законных интересов, которая осуществляется родителями. [2] Именно родители, учитывая положения ст. 63 Семейного Кодекса РФ несут ответственность за воспитание и развитие своих детей и обязаны заботиться о здоровье, физическом, психическом, духовном и нравственном развитии своих детей. [2] Причем указанные права и обязанности родителей сохраняются и после расторжения брака или окончания фактического проживания родителей вместе.

Помимо алиментных обязательств, предусмотренных статьей 80 Семейного Кодекса РФ, родители в соответствии со статьей 86 Семейного Кодекса Российской Федерации, обязаны в отдельных случаях нести дополнительные расходы по содержанию детей. К ним
Рябова Ольга Алексеевна

Преподаватель, ФКОУ ВО «Владимирский юридический институт ФСИН России» frau.lelya2012@yandex.ru Кузнецова Наталья Александровна

Старший преподаватель, ФКОУ ВО «Владимирский юридический институт ФСИН России»

kuz1503@yandex.ru

Матвеева Тамара Павловна

Старший преподаватель, ФКОУ ВО «Владимирский юридический институт ФСИН России»

matveeva33@mail.ru

Кузнецова Наталья Владимировна

Старший преподаватель, ФКОУ ВО «Владимирский юридический институт ФСИН России» kuznezova-1963@mail.ru

Аннотация. Статья посвящена поправкам в статье 86 Семейного Кодекса Российской Федерации о дополнительных расходах, которые обязаны нести родители с целью обеспечения детей пригодным жильем. Высказана позиция об актуальности новации статьи 86 Семейного Кодекса Российской Федерации, как одного из первых регуляторов жилищных проблем детей, закрепленных в законодательном акте такого уровня. Авторами предложены правоприменительные способы реализации норм статьи 86 Семейного Кодекса. Также в статье рассматриваются способы доказывания и виды доказательств необходимости дополнительных расходов на пригодное жилье для ребенка.

Ключевые слова: дети, родители, жилье, дополнительные расходы, пригодное жилье, ответственность.

относятся исключительные обстоятельства, к которым вышеназванная статья причисляет тяжелую болезнь, увечье несовершеннолетних или нетрудоспособных нуждающихся в помощи совершеннолетних, необходимость оплаты постороннего ухода за ними, отсутствие пригодного для постоянного проживания помещения и другие обстоятельства. [2] Осуществление этих расходов предполагается законом на основании соглашения родителей - добровольный способ, который мало востребован и принудительный, то есть судебный.

Важно также отметить, что вопрос о жилье для детей является актуальным в настоящее время. В особенности в случаях, когда речь идет о детях, родители которых по определенным причинам приняли решение расторгнуть брак либо закончить фактические брачные отношения. В подобных ситуациях ребенок становится незащищенным в отношении своих жилищных прав. Если жилье, в котором проживал ребенок, принадлежит роди- 
телю, не проживающему с ребенком, то, зачастую, право пользование таким жильем он теряет. Нормы статьи 31 Жилищного Кодекса РФ, с учетом разъяснений Пленума Верховного Суда от 2 июля 2009 года № 14 [5], о сохранении за бывшим членом семьи права пользования жилым помещением на определенный срок применяются лишь в том случае, когда данный член семьи фактически проживает в спорном жилом помещении.[7,8] Более защищенными в рассматриваемых правоотношениях выступают дети, которые являются собственниками жилых помещений, полностью или частично. Также существует немало иных проблемных моментов в указанных правоотношениях. В правоприменительной практике назрел вопрос о защите детей в подобных ситуациях.

Норма о необходимости в рамках дополнительных расходов обеспечивать ребенка пригодным для постоянного проживания жильем является новацией в российском законодательстве. Необходимые поправки, касающиеся указанного положения, были введены в действие с 17 февраля 2020 года Федеральным законом от 6 февраля 2020 года № 10-Ф3.[6]

В свете указанных изменений возникает вопрос, как норма статьи 86 Семейного Кодекса РФ в части дополнительных расходов на пригодное жилье будет работать и какой режим правоприменения предполагается.

Следует признать, что нередки ситуации, когда дети после прекращения брачных или фактических отношений родителей остаются в сложной ситуации, отягощенной не только моральным аспектом, но и трудностями, возникшими в семье, где остался проживать ребенок, связанными с нехваткой финансовых средств и изменением жилищных условий ребенка в худшую сторону.

Не все российские дети, к большому сожалению, имеют возможность проживать со своими родителями в собственных жилых помещениях. Часты ситуации, когда жилье арендуется семьей, либо проживать приходится со старшими родственниками, либо жилье, в котором проживает семья, принадлежало одному из супругов до брака и еще достаточное количество ситуаций, которые могут продолжить этот список.

И когда родителями принимается решение расторгнуть брак либо прекратить фактические брачные отношения устройство и благополучие семьи разрушается, и ребенок зачастую оказывается в тяжелейшей ситуации. У родителя, с которым остался проживать ребенок не хватает средств, чтобы продолжить арендовать жилье, либо платить коммунальные платежи за имеющееся в собственности, возникают конфликты с родственниками бывшего супруга и т.д.
Имея ввиду вышеописанные ситуации, законодатель попытался повысить ответственность не проживающего с ребенком родителя в отношении нуждаемости ребенка в достойных жилищных условиях.

Учитывая особый статус детей, жилищные права детей - категория весьма специфическая. На протяжении многих лет законодателями не уделялось должного внимания этой проблеме. На настоящий момент мы имеем ситуацию, когда жилищные права детей зачастую прекращаются с расторжением брака родителей за исключением случаев, когда ребенок является собственником целиком или доли жилого помещения. Законодательство Российской Федерации не имеет действенных рычагов воздействия для защиты жилищных прав детей.

Мы полагаем, что в сложившихся условиях внимание правоприменителей и законодателей должно быть направлено на основные способы исполнения родителями дополнительных выплат на пригодное жилье для детей.

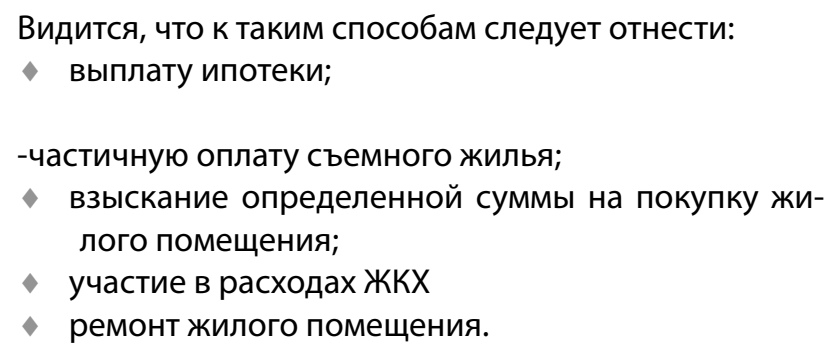

Попробуем разобраться, каким образом при вышеуказанных способах обеспечения детей пригодным жильем надлежит применять нормы статьи 86 Семейного Кодекса РФ. [2]

Безусловно, идеальной является ситуация, если родители между собой смогут заключить соглашение об оплате дополнительных расходов на жилье для детей. Однако процент таких случаев будет очень незначительным. Остальное и подавляющее большинство случаев будет рассматриваться в ходе судебных разбирательств по искам родителей, с которыми остались проживать после развода дети. Система рассмотрения подобных дел должна быть отлажена, судьи должны рассматривать каждый случай с учетом всех особенностей и, в первую очередь, с учетом прав детей, лояльно относясь к родителям-ответчикам, но при проявлениях строгости к желающим обмануть или ввести в заблуждение органы суда и истца, желая уйти от ответственности перед своими детьми.

Выплата части ипотечных платежей, безусловно, должна лечь в основу обязанности родителей по обеспечению детей жильем в рамках статьи 86 Семейного Кодекса РФ. Конечно, при рассмотрении подобных ис- 
ков суды должны очень внимательно выяснять обстоятельства дела. Необходимо выяснять, когда и кем был заключен ипотечный договор, заключен ли он во время брака или уже после его расторжения. Возможно, следует проводить экспертизу жилого помещения с целью определения пригодности его для проживания детей. Следует четко определить, что указанное жилое помещение предназначено и покупалось для обеспечения ребенка нормальными жилищными условиями, являющимися не хуже, чем во время совместного проживания родителей. Вместе с тем, необходимо исключить случаи злоупотребления нормами вышеуказанной статьи. Примером такого злоупотребления может служить требования дополнительных средств на жилье, которое не предназначено для ребенка, а приобретается для нужд родителя, с которым проживает ребенок. Такие случаи необходимо выявлять и пресекать. Безусловно, требуется некоторая корректировка либо дополнение законодательства уточняющими нормами с целью устранения коллизий и единообразия трактовки законодательных актов. Важным моментом в рассматриваемой ситуации будет являться дальнейшая судьба доли в собственности такого жилого помещения. Анализ сложившейся практики показывает, что доли делятся между бывшими супругами, без учета детей. Однако это касается раздела совместно нажитого имущества супругов.[2] Но, учитывая изменения в статье 86 Семейного Кодекса, касающиеся непосредственно прав детей, представляется, что было бы правильным, чтобы оплачиваемая часть жилого помещения впоследствии перешла в собственность ребенка. Дополнительным подтверждением такого решения явилась бы необходимость подписания родителями нотариально заверенного обязательства о передаче доли ребенку в собственность. Это станет документом, который сможет защитить права не только самого ребенка, но и родителей. Вместе с тем необходимо уточнить, что речь идет о доле в жилом помещении, которая оплачивается обоими родителями, а не только тем, который живет отдельно от ребенка. То есть, реализовывая право ребенка на достойное пригодное жилье, родители несут расходы на долю, предназначенную для ребенка, совместно.

Следующим способом взыскания дополнительных платежей на обеспечение детей пригодным жильем может являться частичная оплата арендуемого жилья, в котором проживает или будет проживать ребенок.

Думается, что это будет являться справедливым дополнительным взносом родителя, не проживающего совместно с ребенком. Такая ситуация, когда мама, например, после расторжения брака остается с ребенком в арендуемом жилом помещении и вынуждена либо во многом отказывать ребенку, чтобы это жилье оплатить, либо съехать в более дешевое и менее качествен- ное жилое помещение, что, несомненно, сказывается на условиях проживания ребенка. В каких долях будет распределяться бремя оплаты арендуемого жилья между родителями должен решать суд, но с учетом индивидуальных особенностей спора, материального положения родителей и интересов ребенка. Причем было бы справедливым, если родитель, не проживающий с ребенком после расторжения брака и имеющий доход, серьезно превышающий доход бывшего супруга, проживающего с ребенком, будет нести обязанности по оплате арендуемого жилого помещения в доле превышающей долю такого родителя. Также необходимо отметить, что при вынесении решения, суд может назначить для ответчика не выплату конкретной суммы на оплату жилья, а, скажем, услуг по договору аренды жилого помещения, что будет понятно для родителя - за что он платит и сведет к минимуму количество злоупотреблений стороны, проживающей с ребенком.

Еще одно предложение по взысканию дополнительных средств на пригодное жилье для детей - это покупка жилого помещения. Это, пожалуй, один из наиболее трудно притворимых в жизнь способов обязать родителя участвовать в дополнительных расходах обеспечить ребенка пригодным жильем. Обязать родителя в судебном порядке выплатить определенную и довольно крупную сумму для приобретения жилья сложно, но возможно в исключительных случаях при соответствующей платежеспособности родителей. Что касается собственности на такое жилое помещение, то, безусловно, необходимо решать вопрос о передаче такого жилья либо его части в собственность ребенка, применяя те правила, которые нами были указаны при реализации права ребенка на достойное жилье в рамках статьи 86 Семейного Кодекса при помощи ипотечного кредита.

Следующим предложением по реализации рассматриваемой нами нормы Семейного Кодекса РФ является участие родителя в расходах на оплату коммунальных услуг того жилого помещения, где проживает ребенок. Это важный пункт в реализации норм рассматриваемой нами статьи. Не всегда родитель, проживающий с ребенком, может без усилий оплачивать счета ЖКХ. Это приводит к тому, что приходится отказывать ребенку в привычных и, зачастую, необходимых расходах. Основой при реализации данной меры, которую может принять во внимание суд, могут стать простые математические вычисления. То есть родитель будет нести частично расходы на оплату коммунальных и иных платежей (интернет, телевидение и т.д.) из расчета в них доли ребенка при потреблении этих платежей. В любом случае, суд определит сумму к выплате, учитывая потребности ребенка. Сумма дополнительных расходов может перечисляться родителю, проживающему с ребенком, на специальный счет или банковскую карту. Таким образом, будет 
реализована обязанность родителя по сохранению права ребенка на достойное жилье.

Еще одним способом дополнительных расходов на жилье для ребенка может стать ремонт имеющегося жилого помещения. Ремонт - серьезная статья расхода достаточно дорогое удовольствие и не каждый может себе позволить делать его хотя бы раз в несколько лет. Полагаем, что дети в нашей стране достойны проживать в чистых светлых помещениях с ремонтом. Это не должен быть ремонт с использованием очень дорогостоящих материалов. Это должно быт простое создание уюта в помещении, где проживает ребенок, со свежими обоями, выкрашенными полами, простой и удобной мебелью. Все это родители, хоть и разведенные должны реализовывать сообща, учитывая ст. 61 Семейного Кодекса РФ [2], распределяя между собой соглашением либо через суд степень участия каждого.

Важным аспектом назначения судом выплат на дополнительные расходы является проблема доказывания факта отсутствия у ребенка пригодного для проживания жилья. Так, при расчете нормы жилой площади необходимо руководствоваться статьей 50 Жилищного Кодекса РФ с учетом региональных поправок.[3] Необходимо обследовать жилищные условия ребенка на соответствие их всем необходимым нормам [4] и на основании этого делать вывод о нуждаемости ребенка. Конечно, данный комплекс доказательств будет актуален, если ребенок проживает в жилом помещении. В случае, когда жилье отсутствует, то это и будет являться доказательством нуждаемости ребенка. Также, вероятно, необходимо обследовать жилье на предмет санитарных норм и правил. Безусловно, важным доказательством по подобного рода делам станут экспертные заключения специалистов. Доказательства и система доказывания по искам о взыскании дополнительных расходов на пригодное для детей жилье должны представлять комплекс средств и методов, отличающихся простотой, безусловностью и отсутствием противоречий.

Обобщая все вышеуказанные предложения по реализации норм статьи 86 Семейного Кодекса, следует отметить, что в случаях, когда родители не смогут до- говориться, размер выплат всегда будет определять суд. Разумеется, как уже отмечалось нами, в интересах ребенка, но без злоупотреблений живущего с ним родителя. Суд будет рассматривать необходимость и достаточность выплат, принимая во внимание все обстоятельства. К таким обстоятельствам могут быть отнесены доходы и имущество родителя, находящиеся на его иждивении нетрудоспособные лица, другие дети. Также заслуживающим внимание обстоятельством должно стать отсутствие возможности у лица, обязанного выплачивать алименты трудиться в силу инвалидности или иных серьезных обстоятельств. В то же время, при восстановлении трудоспособности родитель, с которым проживает ребенок, должен иметь возможность повторно инициировать процедуру взыскания дополнительных расходов на реализацию права ребенка на пригодное жилье. С другой стороны, если супруг, проживающий с ребенком, например, предпочитает арендовать жилье класса люкс с арендной платой в несколько десятков тысяч рублей, а у другого родителя доходы не позволяют оплатить ту часть, на которую претендует другой родитель, то суд должен назначит посильную выплату. Видится, что при должном подходе к рассмотрению таких дел в суде будут локализованы попытки злоупотребелний со стороны бывших супругов, так как судебное разбирательство выявит и сделает очевидными все факты злоупотреблений. Нужно отметить, что поправки к статье 86 Семейного Кодекса Российской Федерации в большей степени подарили надежду женщинам, с которыми в подавляющем большинстве случаев остаются после расторжения брака дети. Именно эта категория наиболее уязвима в таких ситуациях. Зачастую женщина остается без работы, с ребенком на руках и без собственного жилья. А бывший супруг, в лучшем случае, платит мизерные алименты и этим его обязательства перед ребенком заканчиваются.

Остается надеяться, что законодатель продолжит вносить поправки подобного рода в семейное законодательство, чтобы установить баланс прав и обязанностей между обоими родителями, который провозглашен статьей 61 Семейного Кодекса РФ[2], но, к сожалению, на практике не работает.

\section{ЛИТЕРАТУРА}

1. К Конституция Российской Федерации (принята всенародным голосованием 12.12.1993) (сучетом поправок, внесенных Законами РФ о поправках к Конституции РФ от 30.12.2008 № 6-ФКЗ, от 30.12.2008 № 7-ФК3, от 05.02.2014 № 2-ФК3, от 21.07.2014 № 11-ФК3) // «Собрании законодательства РФ», 04.08.2014, № 31, ст. 4398

2. Семейный кодекс Российской Федерации от 29 декабря 1995 г. № 223-Ф3 (с изм. от 06.02.2020 № 10-Ф3) // Собрание законодательства Российской Федерации от 1 января 1996 г. $\mathrm{N} 1$ ст. 16

3. Жилищный кодекс Российской Федерации от 29 декабря 2004 г. № 188-Ф3 // Собрание законодательства Российской Федерации от 3 января 2005 г. № 1 (часть I) ст. 14 
4. Положение о признании помещения жилым помещением, жилого помещения непригодным для проживания, многоквартирного дома аварийным и подлежащим сносу или реконструкции, садового дома жилым домом и жилого дома садовым домом. МДС 13-21.2007, утвержденное Постановлением Правительства РФ от 28.01.2006 г. № 47 // Собрание законодательства Российской Федерации от 6 февраля 2006 г. № 6. Ст. 702

5. Постановление Пленума Верховного Суда РФ от 2 июля 2009 г. № 14 «0 некоторых вопросах, возникших в судебной практике при применении Жилищного кодекса Российской Федерации» // Российская газета от 8 июля 2009 г., № 9

6. Федеральный закон от 6 февраля 2020 г. N10-Ф3 «0 внесении изменения в статью 86 Семейного кодекса Российской Федерации» // Собрание законодательства Российской Федерации от 10 февраля 2020 г. № 6 ст. 589

7. Апелляционное определение Московского городского суда от 8.06.2016 по делу № 33-18319/2016, СПС Консультант.

8. Определение Санкт-Петербургского городского суда от 16.10.2012 № 33-13727/2012, СПС Консультант.

9. Распоряжение Правительства РФ от 25.08.2014 N1618-р «0б утверждении Концепции государственной семейной политики в Российской Федерации на период до 2025 года» // Собрание законодательства РФ, от 01.09.2014, № 35, ст. 4811.

10. Кириченко, О.В., Накушнова, Е. В. Права и обязанности граждан — собственников жилых помещений в многоквартирных домах: учебное пособие.«Юстицинформ».- 2019 г.

11. Левшин, Э. М. Нормы морали и права при взыскании алиментов на содержание детей: особенности семейно-правовой диалектики в России / Левшин Э. М. // Семейное и жилищное право. 2019. № 3.- С. 8-11.

12. Далбаева, Н.Н., Буланова, Д.С. Некоторые проблемы обеспечения права ребенка на жилье / Далбаева Н. Н., Буланова Д.С. // Современные проблемы теории и практики права глазами молодых исследователей. 2016. — С. 108-113 13. Ситдикова, Л.Б., Шиловская, А. Л. Исполнение решений суда по определению порядка осуществления родительских прав родителем, проживающим отдельно //Семейное и жилищное право. 2011. № 3. - С. 19-23.

13. Шиловская, А. Л. Медиация как способ внесудебного разрешения семейных споров. //Вестник Московского университета им. С. Ю. Витте. Серия 2: Юридические науки. 2013. № 2(3).—C. 41-45

( Р Рябова Ольга Алексеевна ( ( frau.lelya2012@yandex.ru ), Кузнецова Наталья Александровна ( kuz1503@yandex.ru ),

Матвеева Тамара Павловна ( matveeva33@mail.ru ), Кузнецова Наталья Владимировна ( kuznezova-1963@mail.ru).

Журнал «Современная наука: актуальные проблемы теории и практики»

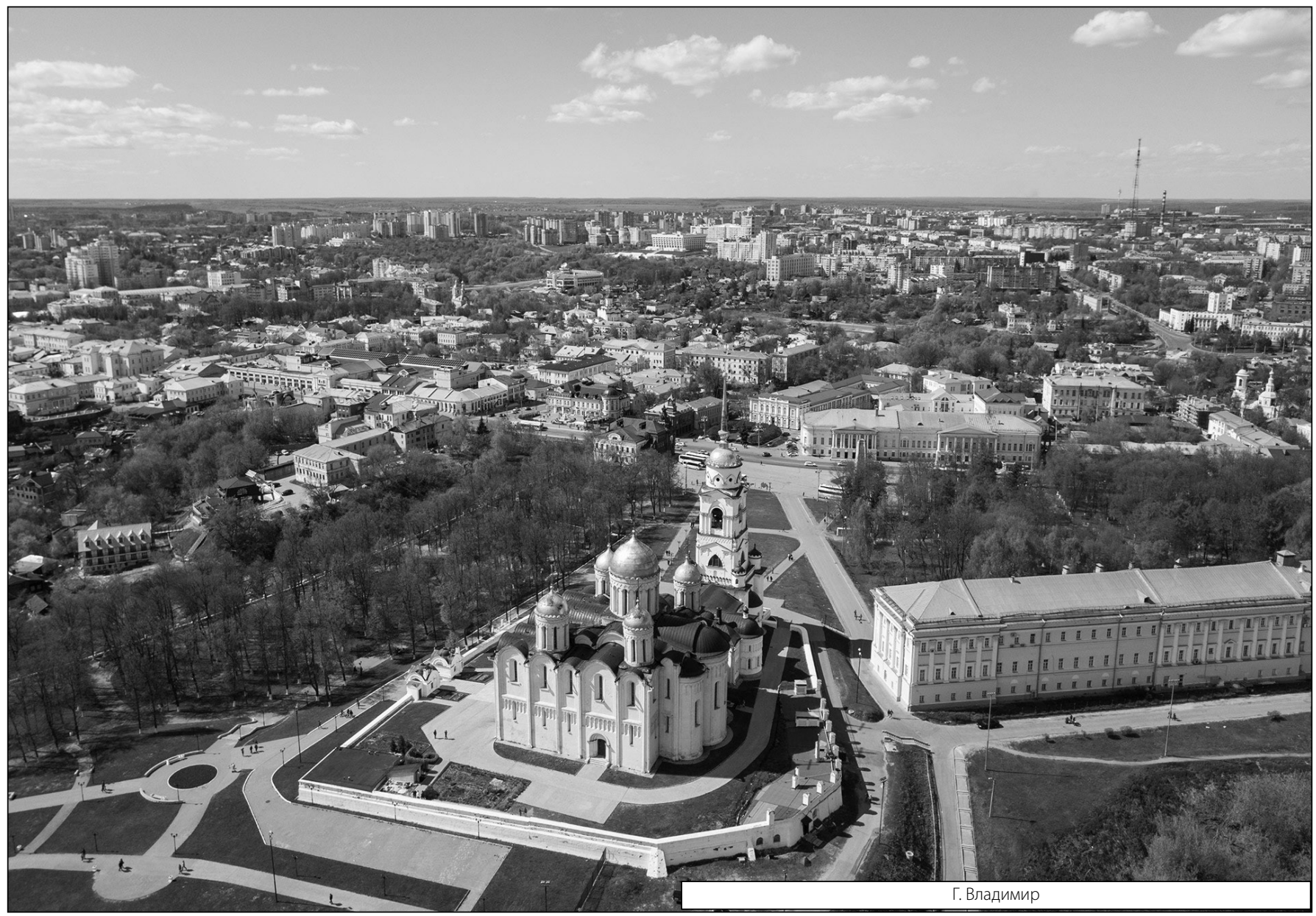

